\title{
Analisis Ketelitian Geometric Citra Pleiades 1B untuk Pembuatan Peta Desa (Studi Kasus: Kelurahan Wonorejo, Surabaya)
}

\author{
Iva Nurwauziyah, Bangun Muljo Sukojo, Husnul Hidayat \\ Jurusan Teknik Geomatika, Fakultas Teknik Sipil dan Perencanaan Institut Teknologi Sepuluh \\ Nopember (ITS) \\ Jl. Arief Rahman Hakim, Surabaya 60111 Indonesia \\ e-mail: bangunms@gmail.com
}

\begin{abstract}
Abstrak-Perkembangan teknologi penginderaan jauh saat ini mengalami kemajuan yang signifikan, salah satunya adalah bertambah baiknya resolusi spasial yang dapat dimanfaatkan sebagai alternatif metode pemetaan dan pemantauan pembangunan pada suatu wilayah dengan skala besar, seperti dasar pembuatan peta desa. Namun, pemanfaatan teknologi penginderaan jauh untuk pemetaan skala besar ini masih terdapat beberapa kesalahan geometric yang harus dieliminasi. Dalam penelitian ini, citra Pleiades 1B dilakukan tinjau ulang sampai sejauh mana ketelitian geometric terhadap kondisi sebenarnya yang akan digunakan sebagai sumber data untuk pembuatan peta desa dengan skala besar. Pada penelitian dilakukan proses rektifikasi dengan menggunakan data titik kontrol tanah (GCP) dengan menggunakan 2 metode yaitu polinomial orde 1 dan orde 2 , selanjutnya dilakukan uji ketelitian geometric pada citra hasil rektifikasi dengan data Independent Check Point (ICP) untuk mengetahui tingkat ketelitian geometric berdasarkan PerKa BIG No. 15 Tahun 2014, sehingga dapat dilakukan analisis mengenai kelayakan citra untuk pembuatan peta desa. Hasil yang diperoleh dari proses rektifikasi citra dengan 8 GCP diperoleh nilai rata-rata RMS metode polinomial orde 2 lebih baik daripada orde 1 . Berdasarkan uji ketelitian geometric pada citra Pleiades 1B terkoreksi, pada metode polinomial orde 1 didapatkan nilai RMSE 0,806 meter dan pada metode polinomial orde 2 didapatkan nilai RMSE 0,647 meter. Untuk kelayakan citra resolusi tinggi untuk pembuatan peta desa berdasarkan Spesifikasi Teknis Pembuatan Peta Desa Tahun 2016 oleh BIG, citra satelit Pleiades 1B memenuhi syarat pembuatan peta desa dengan skala 1:2.500, 1:5.000, 1:10.000.
\end{abstract}

Kata Kunci-Peta Desa, Pleiades 1B, Polinomial Orde 1, Polinomial Orde 2

\section{PENDAHULUAN}

$\mathrm{K}$ ELURAHAN Wonorejo merupakan salah satu wilayah yang masuk dalam wilayah konservasi Pamurbaya (Pantai Timur Surabaya), yang terletak pada koordinat $07^{\circ} 17^{\prime} 56,18^{\prime \prime}$ LS dan $07^{\circ} 19^{\prime} 15,92^{\prime \prime}$ LS serta $112^{\circ} 47^{\prime} 9,63^{\prime \prime}$ BT dan $112^{\circ} 50^{\prime} 43,8^{\prime \prime}$ BT. Luas wilayah kelurahan ini adalah 648,453 Ha. Di Kelurahan Wonorejo ini, terdapat salah satu lokasi pariwisata utama kota Surabaya, yaitu ekowisata mangrove. Wilayah ini telah ditetapkan oleh pemerintah kota Surabaya sebagai area konservasi mangrove dengan tujuan agar kelestarian ekosistem mangrove tetap terjaga. Selain area konservasi mangrove, di kelurahan ini juga terdapat hewan dan tumbuhan lain yang membuat lokasi ini menjadi kawasan wisata [6]. Dengan keberadaan area mangrove yang menjadi wilayah konservasi sekaligus pariwisata, diperlukan adanya informasi geospasial agar dapat mendukung pengelolaan area tersebut, serta dapat digunakan sebagai dasar perencanaan pengembangan kelurahan ini dan untuk mendukung program pembangunan nasional. Informasi geospasial ini dapat disajikan dalam bentuk peta desa [3].

Peta desa merupakan peta tematik bersifat dasar yang berisi unsur dan informasi batas wilayah, infrastruktur transportasi, toponim, perairan, sarana prasarana, penutup lahan, dan penggunaan lahan yang disajikan dalam peta citra, peta sarana prasarana, serta peta penutup lahan, dan penggunaan lahan [3]. Berdasarkan Spesifikasi Teknis Penyajian Peta Desa Tahun 2016 oleh BIG, peta desa ini dapat disajikan pada skala 1:2.500, 1:5.000 dan 1:10.000 dengan sumber data foto udara atau citra satelit resolusi tinggi.

Penelitian ini, melakukan kajian penggunaan citra satelit resolusi tinggi yang merupakan hasil dari teknologi penginderaan jauh untuk pembuatan peta desa berdasarkan Spesifikasi Teknis Penyajian Peta Desa Tahun 2016 oleh BIG. Perkembangan teknologi penginderaan jauh saat ini mengalami kemajuan yang signifikan, salah satunya adalah bertambah baiknya resolusi spasial yang dimiliki oleh citra. Resolusi spasial merupakan ukuran objek terkecil yang masih dapat disajikan atau dibedakan dan dikenali pada citra. Resolusi spasial mencerminkan seberapa rinci suatu sensor yang dipasang pada satelit dapat merekam suatu objek di permukaan Bumi secara terpisah. Semakin besar nilai resolusi spasial yang dimiliki, maka informasi objek yang ditampilkan pada data penginderaan jauh akan terlihat semakin rinci. Kerincian informasi atas suatu objek yang divisualisasikan pada data penginderaan jauh akan memudahkan operator dalam melakukan proses identifikasi suatu objek secara detail. Hal inilah yang menjadi salah satu pertimbangan penggunaan produk citra satelit banyak dimanfaatkan untuk pembuatan peta skala besar [7].

Namun, pemanfaatan teknologi penginderaan jauh untuk pemetaan skala besar masih memiliki beberapa kendala, misalnya perekaman data oleh sensor satelit yang tidak dapat digunakan secara langsung karena masih terdapat beberapa kesalahan geometric yang harus dieliminasi. Oleh karena itu, diperlukan kajian ilmiah yang mengungkapkan seberapa jauh ketelitian geometric citra terhadap kondisi sebenarnya. Berdasarkan data, citra resolusi tinggi Pleiades 1B yang digunakan sebagai bahan penelitian. Citra Pleiades 1B dengan resolusi spasial pankromatik $0,5 \mathrm{~m}$ dan multispektral $2 \mathrm{~m}$ 
dilakukan tinjau ulang sampai sejauh mana ketelitian geometric terhadap kondisi sebenarnya di lapangan, yang nantinya digunakan sebagai sumber data untuk pembuatan peta desa.

\section{URAIAN PENELITIAN}

\section{A. Lokasi Penelitian}

Lokasi penelitian ini dilakukan di wilayah Kelurahan Wonorejo, kecamatan Rungkut, Surabaya yang terletak diantara koordinat $07^{\circ} 17^{\prime} 56,18^{\prime \prime}$ LS dan $07^{\circ} 19^{\prime} 15,92^{\prime \prime}$ LS serta $112^{\circ} 47^{\prime} 9,63$ ' BT dan $112^{\circ} 50^{\prime} 43,8^{\prime \prime}$ BT.

Secara administratif Kelurahan Wonorejo ini memiliki luas wilayah sebesar 648,453 Ha dan berikut adalah batas wilayah Kelurahan Wonorejo:

Sebelah utara : Kelurahan Keputih

Sebelah timur : : Selat Madura

Sebelah selatan : Kelurahan Medokan Ayu

Sebelah barat : Kelurahan Penjaringansari

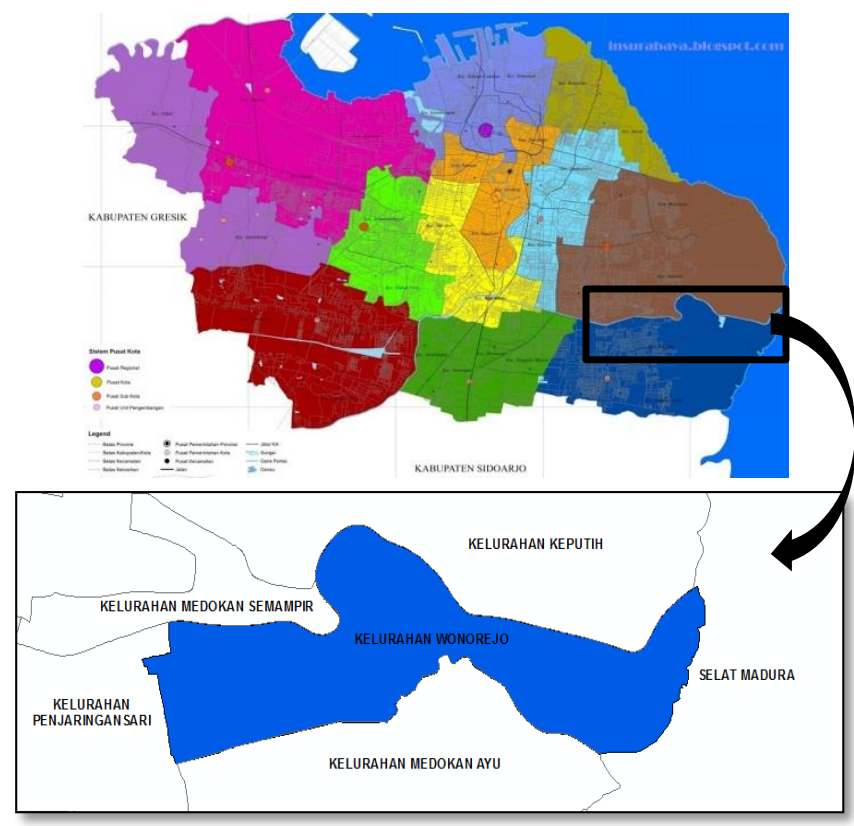

Gambar 1. Lokasi Penelitian

\section{B. Data dan Peralatan}

Data yang digunakan pada penelitian ini adalah citra satelit resolusi tinggi Pleiades 1B tahun 2015 serta data hasil pengukuran lapangan Ground Control Point (GCP) dan Independent Control Point (ICP).

Peralatan yang digunakan pada penelitian ini yaitu:

\section{i. Hardware}

- Laptop

- GPS Geodetik

- GPS Handheld

ii. Software

- Software Pengolah Citra

- ArcGIS 10.2.2

- Matlab R2010a

- Topcon Tools v.7.5.1

\section{Tahap Pengolahan Data}

Tahapan pengolahan data pada penelitian ini digambarkan dalam diagram alir berikut ini:

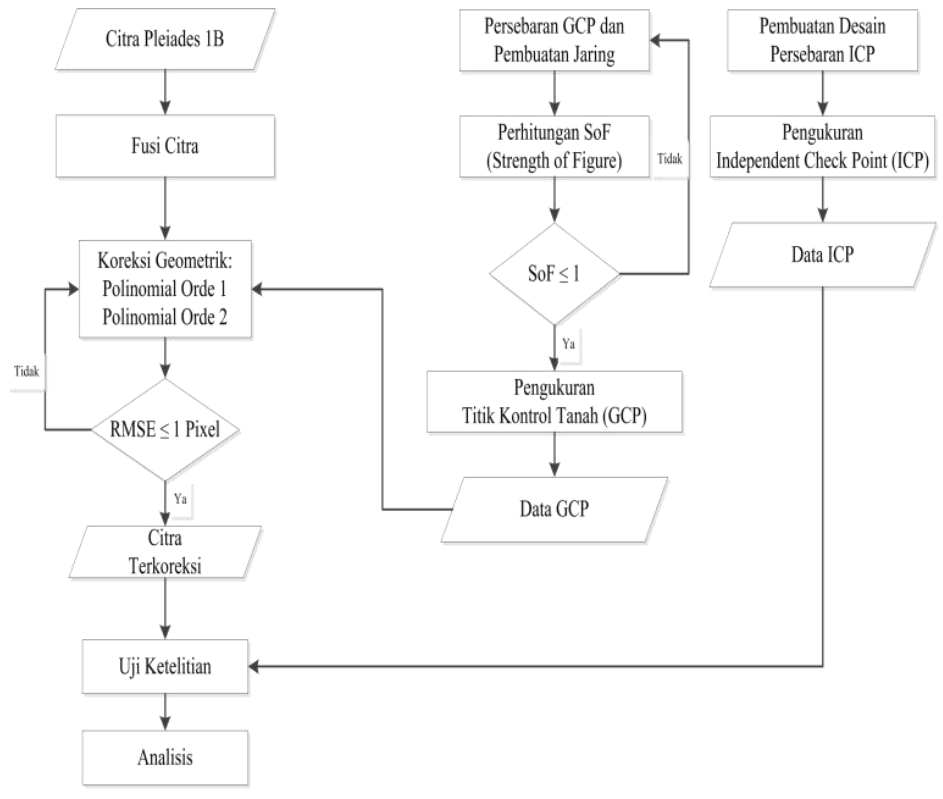

Gambar 2. Diagram Alir Pengolahan Data

Langkah pertama yang dilakukan pada penelitian ini adalah penggabungan (fusi) citra multispektral dan pankromatik menggunakan software pengolah citra, yang bertujuan memperoleh resolusi spektral dan kedetailan informasi spasial yang tinggi sehingga mudah untuk diilakukan interpretasi secara manual.

Langkah selanjutnya adalah pembuatan desain jaring. Pembuatan jaring yaitu pendistribusian secara merata di seluruh wilayah studi dari titik koordinat atau titik GCP yang nantinya akan mempengaruhi hasil koreksi geometric. Distribusi titik yang baik dapat dilihat dari kekuatan jaring yang ditunjukkan dengan nilai SoF (Strength of Figure). Perhitungan SoF (Strength of Figure) dimaksudkan untuk mengetahui tingkat kekuatan geometri dari rangkaian segitiga yang menentukan penyebaran kesalahan dalam perataan jaringan. Hasil perhitungan SoF (Strength of Figure) yang diterima adalah $\leq 1$. Jika kesalahan lebih besar dari persyaratan maka penentuan titik-titik koordinat dan bentuk jaring pada citra dilakukan cek ulang. Rumus perhitungan SoF dengan menggunakan metode parameter adalah sebagai berikut [2]:

Faktor Kekuatan Jaring $=\frac{\operatorname{Trace}\left(A^{T} A\right)^{-1}}{u}$

Dimana, $A$ adalah matriks desain dan $u$ adalah nilai ukuran lebih (redundancy) yang diperoleh dari jumlah ukuran dikurangi jumlah parameter.

Selanjutnya dilakukan pengukuran titik kontrol tanah (GCP) dan titik uji (ICP) dengan menggunakan alat GPS Topcon Hiper Pro. Setelah itu adalah koreksi geometric. Koreksi geometric dilakukan karena terjadi distorsi geometric antara citra hasil penginderaan dan objeknya. Distorsi geometric 
adalah ketidaksempurnaan geometri citra yang terekam pada saat pencitraan, hal ini menyebabkan ukuran, posisi, dan bentuk citra menjadi tidak sesuai dengan kondisi sebenarnya. Distorsi geometric ini harus dikoreksi dahulu sebelum citra digunakan. Pada penelitian ini, melakukan koreksi distorsi geometric dengan menggunakan titik kontrol tanah (GCP). Posisi titik kontrol tanah ditentukan dari beberapa objek yang mudah diidentifikasi pada citra, sehingga diperoleh koordinat dalam sistem koordinat tanah $(\mathrm{X}, \mathrm{Y})$ dan dalam sistem koordinat citra $(\mathrm{x}, \mathrm{y})$ (sebagai titik sekutu). Koreksi geometric pada penelitian ini digunakan dua metode, yaitu polinomial orde 1 dan orde 2. Akurasi dari koreksi geometric ditunjukkan dengan nilai RMSE (Root Mean Square Error) per unit pixel pada citra [5]. Akurasi seharusnya $\leq 1$ pixel, apabila kesalahan lebih besar dari persyaratan, maka kembali melakukan koreksi geometric.

Setelah itu dilakukan analisis ketelitian geometric pada citra Pleiades 1B terkoreksi dengan titik uji (ICP) berdasarkan pada nilai RMSE dan Circular Error (CE90)/Tingkat Ketelitian Horizontal, sehingga dapat diketahui ketelitian geometric pada citra Pleiades 1B terhadap kondisi sebenarnya dan juga dapat dilakukan analisis kelayakan citra satelit resolusi tinggi Pleiades 1B sebagai dasar untuk pembuatan peta desa.

\section{HASIL DAN ANALISA}

\section{A. Hasil Fusi Citra}

Penggabungan citra multispektral resolusi rendah dan citra pankromatik resolusi tinggi merupakan hal yang sangat penting bagi aplikasi penginderaan jauh dan pemetaan. Citra pankromatik memiliki panjang gelombang yang luas mulai dari spektrum tampak dan inframerah dekat, sedangkan citra multispektral hanya mencakup spektrum yang sempit. Akan tetapi, citra multispektral memiliki jumlah lebih dari tiga spektral band, sedangkan citra pankromatik hanya memiliki satu spektral band saja. Sehingga dengan menggabungkan kedua citra tersebut maka diperoleh citra multispektral yang memiliki resolusi spektral yang tinggi dan kedetailan informasi spasial yang tinggi pula. Berikut adalah hasil fusi citra Pleiades 1B:

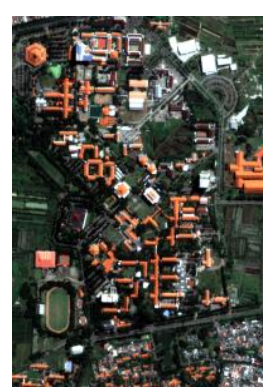

(a)

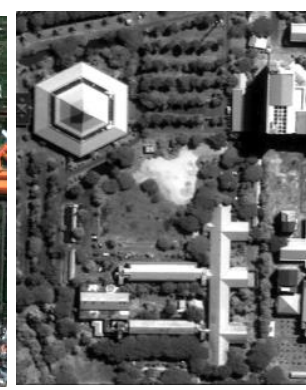

(b)

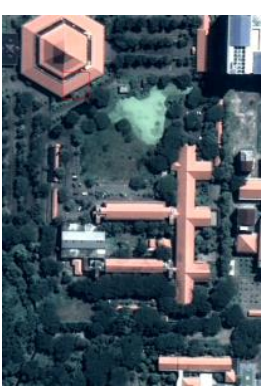

(c)
Gambar 3. (a) Citra Multispektral Pleiades 1B (b) Citra Pankromatik Peliades 1B (c) Hasil Fusi Citra Pleiades 1B

\section{B. Hasil Pembuatan Jaring dan Perhitungan SoF}

Dalam perencanaan proses rektifikasi citra dibutuhkan jumlah titik kontrol tanah yang tepat, agar pelaksanaan pengukuran di lapangan tidak terlalu lama [9]. Penentuan titik
GCP juga diusahakan menyebar hingga posisi terluar dari citra yang akan dilakukan rektifikasi. Pada penelitian ini, jumlah GCP yang digunakan adalah 8 titik. Berikut adalah persebaran titik GCP:

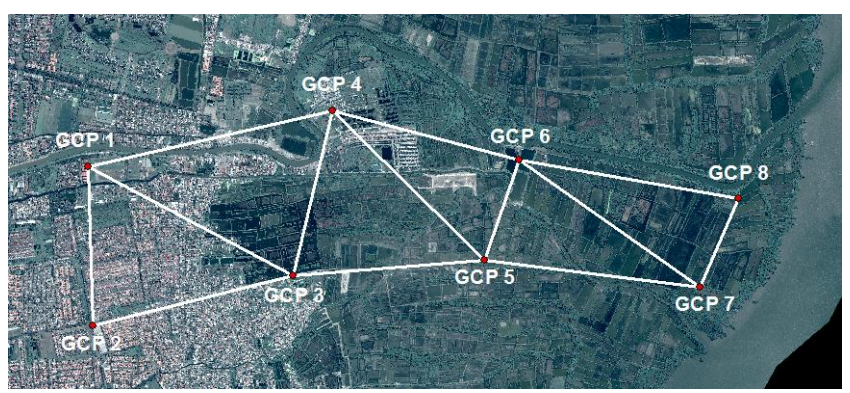

Gambar 4. Persebaran GCP dan Desain Jaring

Dengan desain jaring seperti pada Gambar 5. dan Rujuk ke (1) diperoleh nilai SoF (Strength Of Figure) sebesar 0.5938, dapat dikatakan jika perhitungan SoF memenuhi toleransi yaitu $\leq 1$. Dalam hal ini, faktor kekuatan jaring nilai yang semakin kecil maka akan semakin baik konfigurasi jaringan yang bersangkutan dan sebaliknya [2].

\section{Hasil Pengukuran GCP dan ICP}

GCP dan ICP diukur di lapangan menggunakan alat GPS Topcon Hiper Pro. GCP diukur dengan metode static dengan pengamatan selama 45 menit sedangkan ICP diukur dengan metode rapid static dengan pengamatan 15 menit. Berikut adalah hasil koordinat yang diperoleh dari pengukuran lapangan.

Tabel 1

Data Koordinat Hasil Pengukuran GCP

\begin{tabular}{ccc}
\hline \multirow{2}{*}{ Titik } & \multicolumn{2}{c}{ GROUND CONTROL POINT $(\mathbf{G C P})$} \\
\cline { 2 - 3 } & $\mathbf{X}(\mathbf{m})$ & $\mathbf{Y}(\mathbf{m})$ \\
\hline GCP 1 & 697694,529 & 9191696,257 \\
GCP 2 & 697740,773 & 9190389,810 \\
GCP 3 & 699407,414 & 9190800,332 \\
GCP 4 & 699721,094 & 9192151,699 \\
GCP 5 & 701088,897 & 9190613,219 \\
GCP 6 & 701281,548 & 9191748,465 \\
GCP 7 & 702795,570 & 9190703,690 \\
GCP 8 & 703107,998 & 9191437,327 \\
\hline \hline
\end{tabular}

Tabel 2.

Data Koordinat Hasil Pengukuran ICP

\begin{tabular}{ccc}
\hline \hline \multirow{2}{*}{ Titik } & \multicolumn{2}{c}{ INDEPENDENT CHECK POINT } \\
(ICP)
\end{tabular}


Data hasil pengukuran pada Tabel 1 dan 2. merupakan hasil pengukuran lapangan yang diproses secara post processing dengan menggunakan perangkat lunak Topcon Tools v.7.5.1.

\section{Hasil Koreksi Geometric}

Koreksi geometric bertujuan untuk mereduksi terjadinya distorsi geometric pada citra. Ada beberapa cara untuk melakukan koreksi geometric, yaitu rektifikasi dan registrasi geometric [1]. Rektifikasi citra adalah suatu proses untuk memproyeksikan citra ke bidang datar dan menjadikannya bentuk konform (sebangun) dengan sistem proyeksi yang digunakan, juga memproyeksikan citra yang ada sehingga mempunyai arah yang benar [8].

Hal yang harus diperhatikan saat melakukan rektifikasi adalah pada saat penentuan titik-titik GCP pada citra, diusahakan titik-titik yang akan ditentukan pada citra sesuai dengan titik-titik yang diukur di lapangan sehingga akan didapatkan nilai kesalahan GCP minimum.

Proses rektifikasi menggunakan metode polinomial orde 1 dan orde 2. Pada polinomial orde 1 minimal dibutuhkan 3 GCP dan untuk polinomial orde 2 minimal dibutuhkan 6 GCP, sedangkan untuk polinomial orde 3 dibutuhkan minimal 10 GCP. GCP yang akan digunakan pada penelitian ini adalah 8 GCP, sehingga yang paling sesuai adalah metode polinomial orde 1 dan orde 2 .

Selain jumlah titik kontrol yang tersedia, terdapat juga faktor lain yang mempengaruhi pemilihan orde, diantaranya yaitu keadaan topografi daerah serta kesalahan atau distorsi pada citra yang akan dilakukan [8]. Berdasarkan hasil survei lapangan, topografi wilayah Kelurahan Wonorejo relatif datar dan berada di wilayah pesisir yang sebagian besar wilayahnya berupa tambak.

Pada saat dilakukannya koreksi geometric diperlukan titik kontrol citra (x, y) untuk proses transformasi. Berikut adalah koordinat titik kontrol pada citra satelit Pleiades 1B:

Tabel 3.

Data Koordinat Citra Pleiades 1B

\begin{tabular}{ccc}
\multicolumn{3}{c}{ Data Koordinat Citra Pleiades 1B } \\
\cline { 2 - 3 } Titik & \multicolumn{2}{c}{ TITIK KONTROL } \\
\cline { 2 - 3 } & X $($ Pixel $)$ & Y $($ Pixel $)$ \\
\hline GCP 1 & 15133,5 & 32135,0 \\
GCP 2 & 15237,0 & 34758,5 \\
GCP 3 & 18554,5 & 33906,0 \\
GCP 4 & 19168,0 & 31186,0 \\
GCP 5 & 21906,5 & 34254,0 \\
GCP 6 & 22280,0 & 31970,0 \\
GCP 7 & 25306,0 & 34042,5 \\
GCP 8 & 25922,5 & 32563,5 \\
\hline \hline
\end{tabular}

Untuk mengetahui akurasi dari hasil rektifikasi citra, dapat diketahui dari nilai RMSE (Root Mean Square Error) per unit pixel pada citra. Berikut adalah hasil dari proses rektifikasi citra Pleiades 1B dengan metode polinomial orde 1 dan orde 2:

Tabel 4.

Nilai RMSE Hasil Koreksi Geometric Citra Pleiades 1B dengan 8 GCP

\begin{tabular}{ccc}
\hline \hline \multirow{2}{*}{ Titik } & \multicolumn{2}{c}{ RMSE (Pixel) } \\
\cline { 2 - 3 } & $\begin{array}{c}\text { Polinomial } \\
\text { Orde 1 }\end{array}$ & $\begin{array}{c}\text { Polinomial } \\
\text { Orde 2 }\end{array}$ \\
\hline GCP 1 & 0,328 & 0,231 \\
GCP 2 & 0,309 & 0,136
\end{tabular}

\begin{tabular}{ccc} 
GCP 3 & 0,293 & 0,173 \\
GCP 4 & 0,215 & 0,143 \\
GCP 5 & 0,524 & 0,218 \\
GCP 6 & 0,205 & 0,151 \\
GCP 7 & 0,344 & 0,215 \\
GCP 8 & 0,356 & 0,242 \\
Jumlah & $\mathbf{2 , 5 7 5}$ & $\mathbf{1 , 5 0 8}$ \\
Rata-Rata RMSE (Pixel) & $\mathbf{0 , 3 2 2}$ & $\mathbf{0 , 1 8 8}$ \\
\hline
\end{tabular}

Berdasarkan hasil pengolahan rektifikasi citra, didapatkan nilai rata-rata RMS untuk citra Pleiades 1B dengan 8 GCP adalah 0,322 pixel untuk metode polinomial orde 1 dan 0,188 pixel untuk metode polinomial orde 2. Jadi, proses rektifikasi citra Pleiades 1B dapat diterima karena memenuhi toleransi yang diberikan yaitu $\leq 1$ sebagaimana disarankan.

\section{E. Analisis Nilai RMSE setiap Metode}

Grafik berikut menunjukkan hubungan nilai RMSE setiap titik dari proses rektifikasi citra pada masing-masing metode:

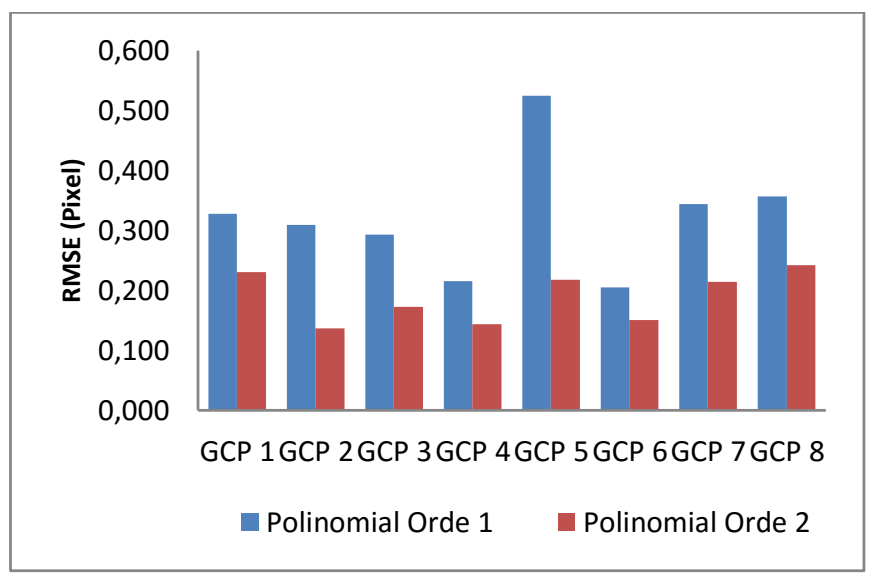

Gambar 5. Grafik Nilai RMSE Hasil Rektifikasi Citra Pleiades 1B dengan 8 GCP

Berdasarkan nilai RMSE pada Gambar 5, nampak bahwa metode rektifikasi citra yang bagus pada penelitian ini adalah metode polinomial orde 2, dimana rata-rata nilai RMSE nya lebih kecil daripada metode polinomial orde 1. Pada citra Pleiades 1B, terdapat 8 GCP (semua titik) pada metode polinomial orde 2 yang nilai nya lebih bagus yaitu mendekati nol dari pada GCP pada metode polinomial orde 1. Hal ini dikarenakan metode polinomial orde 2 dengan 12 parameter merupakan pengembangan dari metode polinomial orde 1 dengan 6 parameter [4].

\section{F. Hasil Uji Ketelitian Geometri}

Uji ketelitian geometri dilakukan dengan menggunakan titik Independent Check Point (ICP) yang berupa koordinat (x, y) hasil pengukuran langsung di lapangan. Jumlah titik ICP yang digunakan adalah 12 titik.

Uji ketelitian geometri ini dilakukan untuk mengetahui nilai ketelitian citra satelit yang telah terkoreksi. Pengujian ketelitian posisi mengacu pada perbedaan koordinat $(\mathrm{x}, \mathrm{y})$ antara titik uji pada citra dengan lokasi sesungguhnya dari titik uji pada permukaan tanah, yang nantinya akan didapatkan pergeseran titik (residu). Dari hasil residu tersebut, digunakan untuk menghitung nilai RMSE koordinat citra. 
Tabel 5.

Hasil Uji Ketelitian Geometric Citra Satelit Pleiades 1B Hasil Rektifikasi Metode Polinomial Orde 1

\begin{tabular}{ccc}
\hline \hline \multirow{2}{*}{ TITIK } & \multicolumn{2}{c}{$\begin{array}{c}\text { Citra Hasil Rektifikasi } \\
\text { Polinomial Orde 1 }\end{array}$} \\
\cline { 2 - 3 } & Residu X (m) & Residu Y (m) \\
\hline ICP 1 & 0,310 & 0,573 \\
ICP 2 & 0,285 & 0,243 \\
ICP 3 & 0,177 & 0,126 \\
ICP 4 & 0,562 & 0,874 \\
ICP 5 & 0,650 & 0,447 \\
ICP 6 & 1,501 & 0,727 \\
ICP 7 & 1,068 & 0,343 \\
ICP 8 & 0,002 & 0,752 \\
ICP 9 & 0,079 & 0,089 \\
ICP 10 & 0,187 & 0,064 \\
ICP 1 1 & 0,482 & 0,169 \\
ICP 12 & 0,681 & 0,301 \\
RMSE (m) & \multicolumn{2}{|c|}{$\mathbf{0 , 8 0 6}$} \\
\hline \hline
\end{tabular}

Tabel 6.

Hasil Uji Ketelitian Geometric Citra Satelit Pleiades 1B Hasil Rektifikasi Metode Polinomial Orde 2

\begin{tabular}{ccc}
\hline \multicolumn{3}{c}{ Metode Polinomial Orde 2 } \\
\hline \multirow{2}{*}{ TITIK } & \multicolumn{2}{c}{$\begin{array}{c}\text { Citra Hasil Rektifikasi } \\
\text { Polinomial Orde 2 }\end{array}$} \\
\cline { 2 - 3 } & Residu X (m) & Residu Y (m) \\
\hline ICP 1 & 0,393 & 0,479 \\
ICP 2 & 0,263 & 0,236 \\
ICP 3 & 0,366 & 0,305 \\
ICP 4 & 0,265 & 0,815 \\
ICP 5 & 0,130 & 0,130 \\
ICP 6 & 0,623 & 0,286 \\
ICP 7 & 1,032 & 0,212 \\
ICP 8 & 0,134 & 0,436 \\
ICP 9 & 0,372 & 0,008 \\
ICP 10 & 0,303 & 0,057 \\
ICP 11 & 0,505 & 0,175 \\
ICP 12 & 0,656 & 0,885 \\
RMSE (m) & \multicolumn{2}{|c}{$\mathbf{0 , 6 4 7}$} \\
\hline \hline
\end{tabular}

Berdasarkan hasil perhitungan RMSE uji ketelitian geometric citra satelit Pleiades 1B terkoreksi, didapatkan nilai RMSE 0,806 pada polinomial orde 1 dan pada polinomial orde 2 adalah 0,647 meter. Hasil RMSE uji ketelitian geometric pada metode polinomial orde 2 lebih bagus yaitu mendekati nol daripada metode polinomial orde 1 , hal ini dikarenakan rata-rata RMS hasil rektifikasi pada metode polinomial orde 2 lebih baik.

\section{G. Analisis Ketelitian Geometri}

Menurut Perka BIG Nomor 15 Tahun 2014, ketentuan ketelitian geometri horizontal untuk pembuatan peta desa adalah:

Tabel 7.

Ketelitian Horizontal Peta Desa

\begin{tabular}{ccccc}
\hline \hline \multirow{2}{*}{ No. } & \multirow{2}{*}{ Skala } & \multicolumn{3}{c}{ (CE90 dalam m) } \\
\cline { 3 - 5 } & & Kelas 1 & Kelas 2 & Kelas 3 \\
\hline 1 & $1: 10.000$ & 2 & 3 & 5 \\
2 & $1: 5.000$ & 1 & 1,5 & 2,5 \\
3 & $1: 2.500$ & 0,5 & 0,75 & 1,25 \\
\hline \hline
\end{tabular}

Nilai CE90 diperoleh dengan rumus berikut:

$C E 90=1,5175 \times R M S E$
Berdasarkan Tabel 7. maka citra satelit resolusi tinggi yang digunakan untuk pembuatan peta desa dikatakan memenuhi standar ketelitian peta desa apabila akurasi horizontal $\leq 5$ meter (kelas 3 ).

Tabel 8.

Hasil Perhitungan Akurasi Horizontal pada Citra Satelit Pleiades 1B

Hasil Perhitungan Akurasi Horizontal Citra Pleiades 1B (m)

Polinomial Orde 11,222

Polinomial Orde $2 \quad 0,982$

Maka, berdasarkan perkalian nilai RMSE hasil uji ketelitian geometric citra satelit Pleiades 1B terkoreksi dengan koefesien ketelitian $(1,5175)$ diperoleh ketelitian horizontal pada citra Pleiades 1B terkoreksi metode polinomial 1B adalah 1,222 meter sedangkan pada pada metode polinomial orde 2 didapatkan akurasi horizontal sebesar 0,982 meter, sehingga berdasarkan Tabel 7, citra satelit Pleiades 1B memenuhi syarat pembuatan peta desa skala 1:2.500, 1:5.000 dan 1:10.000.

\section{KESIMPULAN}

Berdasarkan hasil dan analisa yang telah diuraikan, maka dapat ditarik kesimpulan sebagai berikut:

- Berdasarkan koreksi geometric, pada citra Pleiades 1B dengan metode polinomial orde 1 didapatkan nilai RMSE 0,322 pixel dan dengan metode polinomial orde 2 diperoleh nilai RMSE 0,188 pixel. Pada metode polinomial orde 1 nilai RMSE per titik terkecil sebesar 0,205 dan nilai RMSE per titik terbesarnya adalah 0,524. Pada metode polinomial orde 2 nilai RMSE per titik terkecil sebesar 0,136 dan nilai RMSE per titik terbesarnya adalah 0,242.

- Berdasarkan uji ketelitian geometric menggunakan titiktitik ICP, didapatkan nilai RMSE pada citra Pleiades 1B adalah 0,806 meter pada citra hasil rektifikasi metode polinomial orde 1. Sedangkan citra hasil rektifikasi metode polinomial orde 2 didapatkan nilai RMSE 0,647 meter.

- Untuk kelayakan citra resolusi tinggi untuk pembuatan peta desa, citra satelit Pleiades 1B memenuhi syarat pembuatan peta desa dengan skala 1:2.500, 1:5.000, dan 1:10.000

Saran yang dapat diambil dalam penelitian ini adalah:

- Sebaiknya dilakukan pada waktu yang sama dalam pengukuran GCP dan ICP, sehingga akan meminimalkan pergeseran (residu).

- Menggunakan berbagai rumus transformasi pada saat proses rektifikasi citra.

- Untuk pembuatan peta dengan skala besar dengan menggunakan data citra satelit resolusi tinggi yang memerlukan adanya koreksi geometric sebelum citra tersebut digunakan, maka metode rektifikasi dapat dilakukan dengan menggunakan metode polinomial orde 1 dan memerlukan jumlah minimal GCP sebanyak 3 titik, dimana hasilnya sudah memenuhi toleransi, apalagi dengan menggunakan metode polinomial orde 2 yang memerlukan $6 \mathrm{GCP}$. Hal ini lebih efisien dalam hal pekerjaan lapangan diantaranya waktu, tenaga dan biaya.

- Dalam pembuatan desain persebaran titik GCP dan ICP sebaiknya dilakukan survei lapangan untuk mencocokkan objek di citra dengan objek di lapangan. 


\section{DAFTAR PUSTAKA}

[1] Afifi, Z., 2015. "Studi Pemetaan Fenomena Pemutihan Terumbu Karang (Coral Bleching) Menggunakan Citra Satelit Worldview-2 (Studi Kasus: Perairan PLTU, Probolinggo, Jawa Timur)". Institut Teknologi Sepuluh Nopember, Surabaya.

[2] Anjasmara, I.M. 2005. "Hitung Kerangka Geodesi". Surabaya: Institut Teknologi Sepuluh Nopember.

[3] BIG, 2016b. "Spesifikasi Teknis Penyajian Peta Desa".

[4] Mohammed, N.Z. \& Eiman Eisa. 2013. "The Effect of Polynomial Order on Georeferencing Remote Sensing Images." International Journal of Engineering and Innovative Technology (IJEIT), Vol 2(8), hal. 5-8

[5] Purwadhi, S. H. 2001. "Interpreasi Citra Digital”. Jakarta: Grasindo

[6] Putri, H.K., 2013. "Studi Deskriptif tentang Manfaat Sosial - Ekonomi Ekowisata Mangrove Wonorejo Bagi Masyarakat Kelurahan Wonorejo, Kecamatan Rungkut, Surabaya". Universitas Airlangga, Surabaya.

[7] Rudianto, B., 2010. Analisis Ketelitian Objek pada Peta Citra Quickbird RS 0,68 m dan Ikonos RS 1,0 m. Jurnal Rekayasa, Institut Teknologi Nasional, Vol XIV(3). hal. 156-164. LPPM Itenas. Bandung

[8] Setiadi, Arfian dkk. Uji Ketelitian Hasil Rektifikasi Citra Quickbird engan Perangkat Lunak Global Mapper. Teknik Geodesi Universitas Diponegoro, Semarang

[9] Yudha, I. S, 2015. Studi Jumlah dan Distribusi Titik Kontrol Tanah untuk Proses Rektifikasi Citra Resolusi Tinggi (Studi Kasus : Kota Kediri, Jawa Timur). Tugas Akhir. Surabaya: Jurusan Teknik Geomatika, Fakultas Teknik Sipil dan Perencanaan, Institut Teknologi Sepuluh Nopember 